\title{
Las ferias campesinas y su cuenca alimentaria, de lo imaginado a lo real. El caso de la feria de Collao en el Gran Concepción, Chile
}

\author{
The Farmer markets and their foodshed, \\ from imagination to reality. The case of Collao market in \\ Gran Concepción, Chile
}

\author{
Ana Zazo-Moratalla' y Aaron Napadensky-Pastene²
}

\begin{abstract}
RESUMEN
Las ferias libres son unos espacios efímeros de reocupación del espacio público que ofrecen a sus visitantes una amplia variedad de productos frescos a precio asequible y una suma de experiencias. Dentro de entre ellas, las ferias campesinas añaden la variable ética de ofrecer el acceso a productos de proximidad que provienen de la agricultura local. Este artículo propone entender las ferias campesinas como nodos transitorios de interfaz entre espacio urbano y espacio productivo y toma la feria de Collao ubicada en Gran Concepción (Chile) como caso de estudio. Se realiza el análisis de la conexión campo-ciudad en sus dos sentidos. Por un lado, el sentido rural-urbano que es el que recorren los alimentos, construyendo el mapa de la cuenca alimentaria de la feria, o de los espacios de producción a ella asociados. Por otro lado, el sentido urbano-rural, que es el que poseen los asistentes en su mente al imaginarse de dónde proceden los productos, construyendo el mapa del imaginario territorial. Se parte de la hipótesis de que en las ferias campesinas, al incluir la variable ética, es posible encontrar un alto nivel de coincidencia entre la cuenca alimentaria y el imaginario territorial.

Se recurre a una doble metodología cualitativa. Una para la reconstrucción de la cuenca alimentaria mediante la aplicación de cuestionarios a los feriantes, y otra para la reconstrucción del imaginario territorial realizando entrevistas a los asistentes a la feria. La representación de ambos mapas permite realizar un análisis comparativo de los límites geográficos que refuta la hipótesis planteada. Las discusiones apuntan a develar las razones de las divergencias entre ambas y a reflexionar sobre la maleabilidad de la escala de lo local.
\end{abstract}

Palabras clave: Ferias campesinas, imaginario territorial, cuenca alimentaria, trazabilidad, escala local 


\begin{abstract}
Street markets are ephemeral spaces reoccupying the public space, which offer their visitors a wide range of fresh produce at affordable prices together with the experience they provide. Among these, farmer markets add the ethical variable of offering access to locally grown produce. This article proposes understanding farmer markets as a transitory interface node between the urban space and the productive space, using the Collao market, located in the Greater Concepcion (Chile), as a case study. Analysis is made about the countryside-city connection in two senses. On one hand, the rural-urban sense, which is the route the food takes, building the foodshed map of the market or of the production spaces associated to it. On the other hand, the urban-rural sense, which is related to the one those who go there have in their minds, on imagining where the produce comes from, building the map of the territorial imaginarium. It starts from the hypothesis that in countryside markets, on including the ethical variable, it is possible to find a high level of coincidence between the foodshed and the territorial imaginarium A double qualitative methodology is used. One to rebuild the foodshed by applying questionnaires to the market sellers, and another to rebuild the territorial imaginarium on interviewing those who go to the market. The representation of both maps allows making a comparative analysis of the geographical limits that refute the hypothesis proposed. The discussions aim at revealing the reasons behind the divergence between both and to reflect upon the malleability of the local scale.
\end{abstract}

Keywords: Farmer markets, territorial imaginarium, foodshed, traceability, local scale

\title{
Introducción
}

Las ferias libres han sido y siguen siendo un espacio de reunión que ofrece a sus visitantes una amplia variedad de productos, una diversidad de colores y una suma de experiencias, detonando un proceso de reocupación del espacio público que enriquece la experiencia urbana de los asistentes y de los residentes (Utreras, 2013). Las razones por las que algunos ciudadanos urbanos eligen seguir apostando por este tipo de consumo pre-moderno frente a otras opciones de abastecimiento primario más estandarizado e industrializado pueden clasificarse en tres: (i) razones hedónicas (Peñaloza et al, 2015) buscando el placer, la diversión y las experiencias sensoriales; (ii) razones utilitarias que implican conseguir una buena relación calidad-precio (Kirwan, 2004); y (iii) cuestiones éticas que denotan la preocupación por los efectos del consumo individual (Linders, 2013) y que incluye la preferencia de consumo de productos de un ámbito local y el apoyo a la economía agraria de pequeña escala. Las ferias libres que reunen estas tres características son las ferias o mercados campesinos.

En Chile la primera aparición de una feria libre con las características actuales fue hace 220 años en La Serena, sin embargo, hasta principios del siglo XX las ferias libres no se generalizaron como método de descentralización de los mercados de abastos y de control de precios (Salazar, 2003). En la actualidad, existen 1.114 ferias libres en el ámbito nacional, concentrando la Región Metropolitana el mayor número de ellas (455) y ocupando la antigua Región del Bío Bío la segunda posición (143) (SERCOTEC, 2016).

En el Área Metropolitana de Concepción (AMC en adelante), con cerca de un millón de habitantes, existe una constelación de 32 ferias libres alimentarias que nutren y abastecen a su población (SERCOTEC, 2016). La mayoría responden a una lógica profesionalizada en la que los feriantes forman parte de un sistema de distribución alimentaria de escala nacional (ODEPA, 2009), 
adoptando un papel de intermediario en una cadena en la que resulta casi imposible analizar la trazabilidad de los alimentos. Sin embargo, cuatro de ellas han sido identificadas como ferias campesinas (Zazo y Troncoso, 2018). Estas ferias proporcionan a la población urbana alimentos frescos, de calidad y de proximidad, cumpliendo una labor clave en términos de economía solidaria (Roldán et al, 2016) y de mejora de la soberanía alimentaria de las comunas en las que se ubican: Tomé, Santa Juana, Penco y Concepción. De entre ellas, destaca la feria de Collao, ubicada en Concepción, por reunir un mayor número de puestos campesinos -40 frente a los 20 del resto-, celebrarse con una asiduidad mayor - tres veces por semana, mientras que el resto lo hace semanal o mensualmente $-y$ atraer a más población urbana.

Frente a otros estudios que analizan estos mercados desde su perspectiva urbana, espacios efímeros (Hidalgo et al, 2016) su ubicación en el ámbito urbano (Mora, 2003) o nodos de centralidad transitoria en el espacio urbano (Troncoso, 2009), este artículo propone entender las ferias campesinas como nodos transitorios de conexión entre el campo y la ciudad. Esto supone entenderlos como una interfaz entre el espacio urbano -y las personas que en él habitan- y el espacio productivo de un ámbito local sin una escala definida $-y$ las personas que en él trabajan. Esta conexión tiene dos sentidos. Por un lado, el sentido rural-urbano, que es el que recorren los alimentos desde su origen en el espacio productivo hasta la feria como espacio de comercialización. La transparencia de este proceso se denomina trazabilidad (Peters et al, 2009) y la reconstrucción de ese proceso es el de la construcción de la cuenca alimentaria (Getz, 1991). Desde otra perspectiva, en un sentido urbano-rural puede reconstruirse el imaginario territorial del espacio productivo que poseen las personas que acuden a la feria. La primera, una cuenca alimentaria real, la segunda, una cuenca alimentaria imaginada construida en base al nivel de intercambio de información establecido entre ciudadanos y comerciantes. Bajo este enfoque, se plantea como hipótesis que en las ferias campesinas es posible encontrar un alto nivel de coincidencia entre la cuenca alimentaria real y la imaginada, debido a la introducción de la dimensión ética junto a la hedónica y utilitaria.

Para comprobar la hipótesis se toma en este estudio el caso de la feria de Collao donde se aplica una doble metodología cualitativa. Una para la reconstrucción de la cuenca alimentaria aplicando cuestionarios a los feriantes y otra para la reconstrucción del imaginario territorial aplicando entrevistas a los asistentes a las ferias. La representación de ambos mapas, real e imaginado, permitirá realizar un análisis de los límites geográficos de ambas cuencas, de sus escalas, de sus coincidencias y de sus divergencias. Los resultados obtenidos refutan la hipótesis planteada y las discusiones se orientan a buscar razones para ello.

\section{Marco teórico}

\section{Las ferias campesinas como reductos de consumo premoderno}

La existencia de la ciudad ha estado ligada desde sus orígenes al comercio (Mitre, 2013). Su evolución durante los dos últimos siglos ha mantenido los espacios de consumo como eje vitalizador urbano, sin embargo, los ha adaptado al marco contextual inserto, transformándolos de un modo de consumo premoderno a uno moderno y posteriormente contemporáneo. A finales del siglo XIX el geógrafo Ratzel (1891) definió la ciudad en la historia como reunión duradera de 
hombres y viviendas humanas que se encuentra en la encrucijada de grandes vías comerciales. Unos años después, la ciudad se describió como concentración de personas cuyos medios de existencia consisten en formas de trabajo no consagradas a la agricultura, sino al comercio y a la industria (Richthofen, 1908). Estas personas no se dedicaban, de forma directa, a la obtención de materias primas alimentarias, textiles o de confort en general, sino que se encontraban vinculadas a otro tipo de actividades como el comercio, el transporte, la industria, la instrucción de la población o la administración del estado (Aurosseau, 1921).

Con la revolución industrial, la expansión de la producción de bienes en serie y la generación de excedentes, surge a fines del siglo XIX en París (Francia) una nueva tipología comercial de inédita escala, los grandes almacenes. Estos espacios comerciales se ubicaron en los centros urbanos tradicionales de países industrializados, inaugurando con ellos la era del consumo moderno (Miller, 1995; Campbell, 1995; Bell, 2006) que se asentó durante la primera mitad del siglo XX. A mitad de este siglo, surge y prolifera en las periferias norteamericanas otra nueva tipología de espacio de consumo que determina el fin del consumo moderno dando paso a uno contemporáneo: el shopping mall o centro comercial. Estos nuevos espacios, en su masividad y gran despliegue, han instaurado durante la segunda mitad del siglo XX y comienzos del XXI una hegemonía en el ámbito internacional que da cuenta de la relevancia que ha alcanzado el consumo dentro de la vida cotidiana contemporánea.

En esta última etapa contemporánea de las sociedades urbanas, lo masivo es reemplazado por lo multitudinario, transformando la estandarización de lo masivo, a la personalización de lo múltiple (Baudrillard, 1969; Lipovetsky, 2007), marcando la aparición de un nuevo consumo y consumidor contemporáneo (Sennett, 2006). Ya satisfechas las necesidades básicas, o utilitarias, el nuevo consumidor busca experiencias hedónicas o de bienestar sensitivo, emotivo y lúdico, redefiniendo su relación con los lugares de consumo y pasando de ser un consumidor pasivo, propio de la sociedad industrial, a uno activo, propio de las economías de consumo (Verdú, 2007; Goss, 1993; Lipovetsky, 2007; De Certeau, 2002).

En este contexto, la venta de productos fresco, no durables, y sus cadenas de distribución, igualmente fueron cambiando hasta llegar a los grandes hipermercados de la actualidad, que suelen estar asociados a shjpping mall. Sin embargo, persisten algunos bastiones de consumo premoderno que han subsistido a estos cambios estructurales y que, con el surgimiento de este nuevo consumidor, más hedonístico, más experiencial, pero, sobre todo, más ético han tenido un nuevo brío (Linders, 2013). Estos espacios son las ferias campesinas, nodos efímeros de venta de productos agroalimentarios de proximidad, donde en la mediación entre vendedor y comprador, feriante y ciudadano, sigue vigente como una cohesión socioeconómica entre población rural y urbana, entre campo y ciudad (Bernabé, 2002). En esta mediación son básicos los aspectos utilitarios y hedónicos de la compra, pero implica una tercera dimensión ética que orienta la toma de decisiones en la compra de productos alimentarios.

\section{Las ferias campesinas, de lo imaginado a lo real}

Las ferias campesinas se definen como un espacio de consumo, pero también como un constructo social que evoca una ruralidad nostálgica (Bell \& Beeston, 2011) y en el que las percepciones que tienen los concurrentes en relación a los productos agroalimentarios que ahí se ven- 
den se transforman en representaciones territoriales, que mediante un proceso simbólico se constituyen potencialmente en imaginarios espaciales (Lindón, 2007) fijando e identificando los productos a lugares determinados. Bajo el supuesto de que los imaginarios territoriales fuesen coincidentes entre los individuos que la frecuentan, podría decirse que este se trataría de un imaginario social, en tanto es una manera compartida de representar el espacio y el tiempo (Lindón, 2007; Márquez, 2007). Imaginar es una intención dirigida a un objeto ausente (Márquez, 2007), y cuando esta imagen se construye e instituye como un imaginario social, tiene la capacidad de influir y orientar las prácticas y discursos, incidiendo en una determinada legibilidad del territorio local. Sin embargo, en muchos casos, estos imaginarios son dibujados desde la nostalgia, contribuyendo a una hipertrofia de la memoria, generando una imagen que a menudo amplifica y transforma el acontecer (Márquez, 2007).

Por otra parte, las ferias campesinas son el resultado de un circuito corto alimentario (Kirwan, 2004) que vincula por medio de los alimentos un espacio de producción de proximidad con un nodo transitorio de comercialización de productos frescos. Este enfoque pone el acento sobre un suelo agrario productivo, con sus agentes económicos y conflictos territoriales, que actúa como la estructura territorial de abastecimiento de este espacio de consumo efímero. Esta estructura de soporte se denomina cuenca alimentaria $(G e t z, 1991)$ y su reconstrucción implica la visualización de la trazabilidad de la cadena agroalimentaria. Su representación territorial implica poder vislumbrar los límites geográficos de esta estructura y dar una escala al término "local" (Zazo et al., 2019) que, usualmente, es bastante maleable (Paül \& McKenzie, 2013). A largo plazo, esta delimitación puede implicar determinar políticas alimentarias localizadas (Morgan, 2009) para fomentar estos espacios de producción asociados a los nodos de venta de proximidad.

\section{Estudio de caso}

\section{El Área Metropolitana de Concepción}

El Área Metropolitana de Concepción (AMC) es la segunda conurbación más grande de Chile, con una población de casi un millón de habitantes. Se localiza en la costa de la Región del Biobío y se compone de 11 comunas con una organización jerárquica distribuidas de forma tentacular en la que Concepción actúa como centro de servicios.

Concepción y en sus comunas aledañas fueron beneficiarias a mediados del siglo XX de una política de estímulos gubernamentales descentralizadores que buscaba desarrollar industrialmente el territorio y que tuvo efectos en importantes ciudades medias. En el AMC estas acciones expandieron su producto interno bruto y aumentaron su población (Hernández, 1983; Aliste y Almendras, 2010), sentando las bases de lo que posteriormente se conocería como Gran Concepción, y en la actualidad como Área Metropolitana de Concepción (AMC). Transcurrido más de medio siglo, y ya entrado el siglo XXI, es posible apreciar, no sin contradicciones e inestabilidades, una consolidación de esta metrópolis intermedia funcionalmente compleja que se levanta como una de las más importantes a nivel nacional después de Santiago, capital de Chile (Napadensky, 2016).

El AMC, junto con mantener la vitalidad de los centros tradicionales, ha ido produciendo nuevas jerarquías funcionales y experienciales (Napadensky y Rivera, 2015), dando cuenta de una 
complejidad funcional relevante (Napadensky y Orellana, 2019), donde emergentes funciones terciarias que cohabitan con usos industriales, manufactureros e incluso remanentes rurales. Todas estas funciones se materializan en un crisol de usos y funciones particularmente complejos dentro del área metropolitana, donde destacan espacios intersticiales dedicados a la agricultura y a otras funciones ambientales.

\section{La feria libre de Collao}

La feria libre de Collao se desarrolla en Concepción, capital del AMC y único municipio sin uso del suelo agrícola dedicado a actividades productivas profesionales. Se trata de la feria libre urbana más grande e importante del área metropolitana, ya que en ella confluyen más de 100 puestos y atrae a cientos de ciudadanos. Su periodicidad es de tres veces por semana en un espacio originalmente dedicado a estacionamiento del estadio Esther Roa Rebolledo, el más grande de la metrópolis.

\section{Figura N01}

Ubicación en el ámbito metropolitano e imagen de la feria de Collao en Concepción.

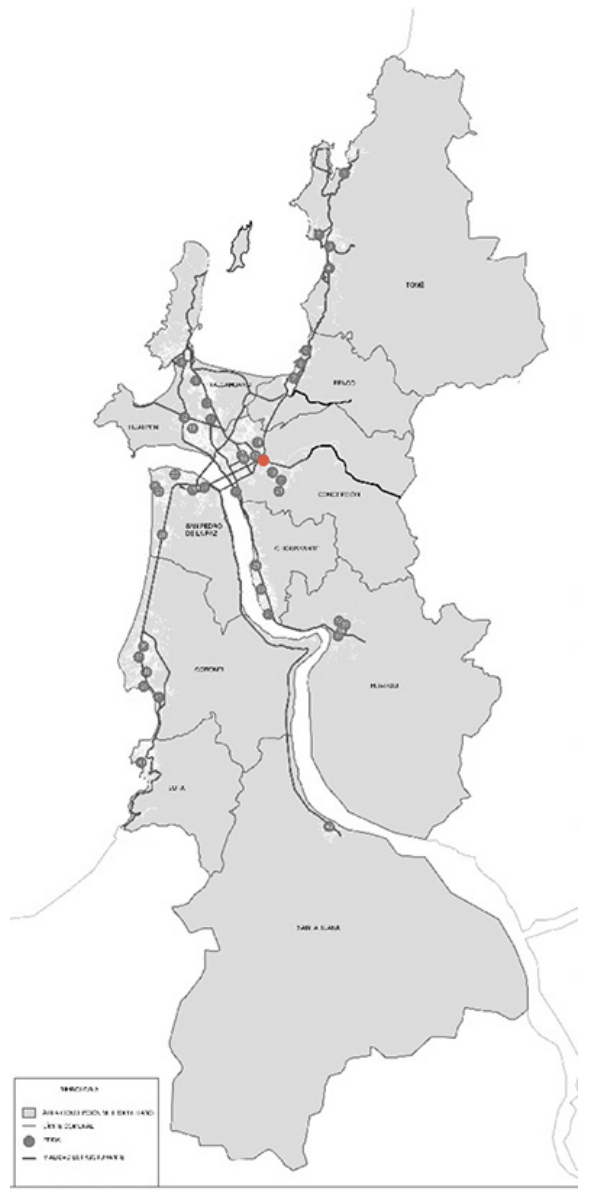


La particularidad de la feria de Collao es su doble naturaleza, campesina y profesionalizada; iferenciandose por su distribución de puestos en el espacio urbano y por el tipo de toldos utilizados. Los puestos campesinos se organizan en un sindicato agrario denominado "Despertar Campesino" que aglutina a campesinos de proximidad y supone aproximadamente la mitad de los puestos de la feria. Esta parte de la feria proporciona a la ciudadanía alimentos locales y calidad sometidos a la estacionalidad ya las limitantes climáticas de la región. En este caso la cadena agroalimentaria detrás de cada feriante, y puesto, es un circuito corto en el que hay como máximo un intermediario y cuyo origen posee una proximidad indeterminada, hasta ahora.

La otra parte de la feria libre es la profesionalizada, compuesta por feriantes que transitan por las diversas ferias metropolitanas y que adquieren sus productos en el gran nodo logístico agroalimentario de la metrópolis, la Vega Monumental. Este nodo proporciona alimentos que provienen de diversos orígenes nacionales e internacionales, no sujetos a estacionalidad y con un número indeterminado de intermediarios entre origen y feria. Para mantener un precio competitivo al final de la cadena, el rédito de los productores es menor por volumen de productos que en el caso de los feriantes campesinos, que provienen de una agricultura de pequeña escala que proporciona la proximidad como valor agregado de sus productos.

La feria de Collao, como representativa en el AMC desde su característica campesina y bajo el enfoque de espacio conector entre el campo y la ciudad, se presenta como una oportunidad para explorar su relación con los espacios agrarios intra-metropolitanos y de proximidad, y profundizar en el conocimiento que los ciudadanos poseen de esta compleja realidad metropolitana.

\section{Metodología}

La investigación propuesta requiere del diseño de dos bloques metodológicos que darán como resultado dos bloques de resultados a comparar, el del imaginario territorial -o cuenca alimentaria imaginaria-, y el mapa de la estructura territorial de abastecimiento alimentario a la feria -o la cuenca alimentaria real.

\section{Determinación y representación del imaginario territorial de la feria de Collao}

El primer bloque metodológico se centra en la determinación y representación del imaginario territorial de proximidad vinculado a la feria de Collao. Para ello, se utilizará como técnica la entrevista estructurada de carácter no probabilístico y se aplicará a personas que asisten a la feria como mínimo una vez al mes y al menos desde hace tres años. La muestra no se establece a priori si no que se ajusta por saturación de las respuestas, saturación alcanzada a las 10 entrevistas.

La entrevista se divide en tres bloques. El primero, centrado en los vínculos con la feria y las rutinas de los asistentes, en el que se le plantean diversas preguntas abiertas. El segundo, centrado en las razones por las que los asistentes acuden a la feria. Este bloque pretende determinar cuáles son las características que más asocian a la feria y que configuran el imaginario social vinculada a ella. Se realiza una primera pregunta abierta sobre por qué eligen este espacio de consumo premoderno frente a otras opciones. Después, se les solicita priorizar entre las cuatro siguientes 
opciones: productos frescos de calidad, bajo precio, productos locales o comercio justo. Los dos primeros se vinculan con razones utilitarias y los dos últimos se vinculan con razones éticas. Se descartan para este análisis las razones hedónicas porque son las compartidas con los espacios de consumo contemporáneo con los que se están queriendo diferenciar las ferias campesinas.

El último bloque profundiza en la dimensión territorial del imaginario determinando el nivel de abstracción o concreción de su territorialización. Se analiza si los encuestados vinculan los alimentos que se adquieren en la feria a espacios agrarios del ámbito metropolitano-regional o a otros ámbitos geográficos. Para ello, se selecciona un grupo de alimentos que incluyen productos frescos y transformados, así como productos característicos de determinadas comunas del ámbito regional, y se les solicita que identifiquen las comunas proveedoras que abastecen de esos alimentos a la feria. Los alimentos seleccionados son los siguientes: choclo, papas, tomates, lechuga, miel, poroto, queso, aceitunas, manzanas, sandías, cerezas, membrillos y brócoli.

Las entrevistas se transcriben y tabulan de modo que, por un lado, quedan determinados los porcentajes de las principales razones por las que las personas acuden a la feria. Por otro, quedan identificadas los porcentajes a los que las personas atribuyen el origen de los alimentos de la feria: local u otras áreas de Chile. Finalmente, quedan identificadas aquellas comunas nombradas como proveedoras de determinados productos. Estos últimos datos se traducen a una tabla Excel en el que las filas son las comunas del ámbito regional del Bío Bío y las columnas son los productos. Esta tabla se asocia por medio de Sistema de Información Geográfica a la capa de las comunas regionales para representar aquellas asociadas al imaginario territorial vinculado a la feria de Collao. Se construye, así, un mapa cualitativo donde se representan las comunas identificadas por los entrevistados en el que la importancia es tanto la presencia como la ausencia de las comunas en el imaginario.

\section{Determinación y representación de la cuenca alimentaria de la feria de Collao}

El segundo bloque metodológico se centra en la construcción del mapa de la cuenca alimentaria real de la feria de Collao. Para ello, se utiliza como técnica la encuesta y se aplica al $100 \%$ de los feriantes de los puestos vinculados al sindicato el "Despertar campesino" asistentes en sábado por la mañana, día de mayor afluencia de feriantes.

La encuesta se centra en la realización de un catastro de los productos que cada feriante tiene en el puesto para, posteriormente, registrar el origen de cada uno de ellos. Este bloque metodológico posee el limitante de que la encuesta fue realizada en temporada invierno 2017 (julio-agosto-septiembre) durante los cuales la región del Bío Bío tiene una menor capacidad productiva de vegetales. Puesto que el imaginario con el que se va a comparar es atemporal, se trató de superar este limitante incluyendo una pregunta adicional en el cuestionario en el que se preguntaba por los productos que los feriantes-agricultores producen y comercializan durante el verano, registrando el origen. Es necesario asumir que esta respuesta podría tener un sesgo del recuerdo, ya que la fuente de información fue el relato de los feriantes.

Para esta investigación, sólo se tabularon los productos que habían sido incluidos en la entrevista del primer bloque metodológico, de modo que los resultados fueran comparables. Esta 
tabulación generó dos tipos de tablas. La primera, identifica a los feriantes y les asocia con los productos que venden y las comunas de origen. La segunda tabla unifica los datos de modo que en las filas aparecen las comunas del ámbito regional y en las columnas aparecen los alimentos. Esta tabla se asocia mediante Sistema de Información Geográfica a la capa de comunas utilizada en el bloque anterior, de modo que se represente el mapa de la cuenca alimentaria real de los productos seleccionados que se comercializan en la feria.

\section{Metodología para el análisis comparativo entre la cuenca alimentaria real e imaginada de la feria de Collao}

Con el objeto de comparar los dos resultados anteriores se desarrollan los siguientes productos: (i) Tabla comparativa del origen imaginario y real de los productos; (ii) Cálculo y representación de los radios máximos de alcance del imaginario y de la cuenca real; (iii) Mapa de las coincidencias entre lo imaginario y lo real; (iv) Mapa del imaginario y de las comunas que pertenecen al gran corredor agroalimentario nacional del valle central de Chile.

\section{Resultados}

\section{El imaginario territorial de la feria de Collao}

Los resultados obtenidos en las entrevistas realizadas en el primer bloque metodológico en relación a las razones por las que las personas acudían a la feria se resumen en el Cuadro N01. La mitad de las personas declara como prioritaria algún aspecto utilitario mientras que la otra mitad declara algún aspecto vinculado a la ética. Dentro de los aspectos utilitarios, la compra de productos frescos se posiciona como una razón doblemente prioritaria que el precio de los productos y dentro de los aspectos éticos la compra de productos locales se declara el doble de veces que la compra de alimentos a agricultores locales que buscan encontrar un mayor acercamiento a los productores a través de canales cortos y recibir un mejor rédito por su trabajo. Esto implica varias cosas. En primer lugar, que la decisión prioritaria de comprar en la feria de Collao no son razones económicas, ni vinculadas al bolsillo familiar, ni al de los productores, si no que se vincula principalmente con hábitos de alimentación saludable y con la existencia de un imaginario territorial de proximidad vinculado a los alimentos de la feria.

Cuadro No 1

RAZONES POR LAS QUE LAS PERSONAS ACUDEN A LA FERIA DE COLLAO

\begin{tabular}{|l|l|r|r|}
\hline \multirow{2}{*}{ Aspectos utilitarios } & Productos frescos de calidad & $33,3 " \%$ & \multirow{2}{*}{$50 \%$} \\
\cline { 2 - 3 } & Bajo precio de los productos & $16,7^{\prime \prime} \%$ & \\
\hline \multirow{2}{*}{ Aspectos éticos } & Productos locales & $33,3^{\prime \prime} \%$ & \multirow{2}{*}{$50 \%$} \\
\cline { 2 - 3 } & Comercio justo & $16,7^{\prime \prime} \%$ & \\
\hline
\end{tabular}

Fuente: elaboración de los autores.

Por otra parte, los resultados obtenidos en relación a la determinación y delimitación del imaginario territorial de la feria de Collao se dividen en dos partes y se resumen en el Cuadro $\mathrm{N}^{2} 2$. 
Los entrevistados identificaron de forma genérica el origen de los productos que pueden encontrar en la feria. Alrededor del $60 \%$ exponía que los productos que compraban en la feria provenían de otras regiones de Chile, principalmente del Norte donde el clima es más cálido y existen grandes áreas hortofrutícolas que producen durante todo el año. Sólo algunas respuestas marginales identificaron el sur de Chile como el origen de estos alimentos. Por otra parte, un $40 \%$ identificó que los productos de la feria provenían del área local. Esto implica que menos de la mitad de las personas entrevistadas comparte la existencia de un imaginario territorial de escala local asociado a la feria de Collao, siendo lo local una escala no definida ni delimitada. Complementariamente, el $60 \%$ de las personas entrevistadas, o bien no se lo había planteado esta dimensión, o directamente lo asocia a los circuitos alimentarios de escala nacional que se vinculan con las grandes áreas productivas de Chile, diluyendo en gran medida la dimensión territorial.

Por otra parte, el tercer bloque de preguntas de la entrevista permitió matizar estos resultados y determinar el nivel de territorialización que los entrevistados que identificaron lo "local" como el

Figura $\mathrm{N}^{\circ} 2$

Dimensión territorial del imaginario social vinculado a la feria de Collao.

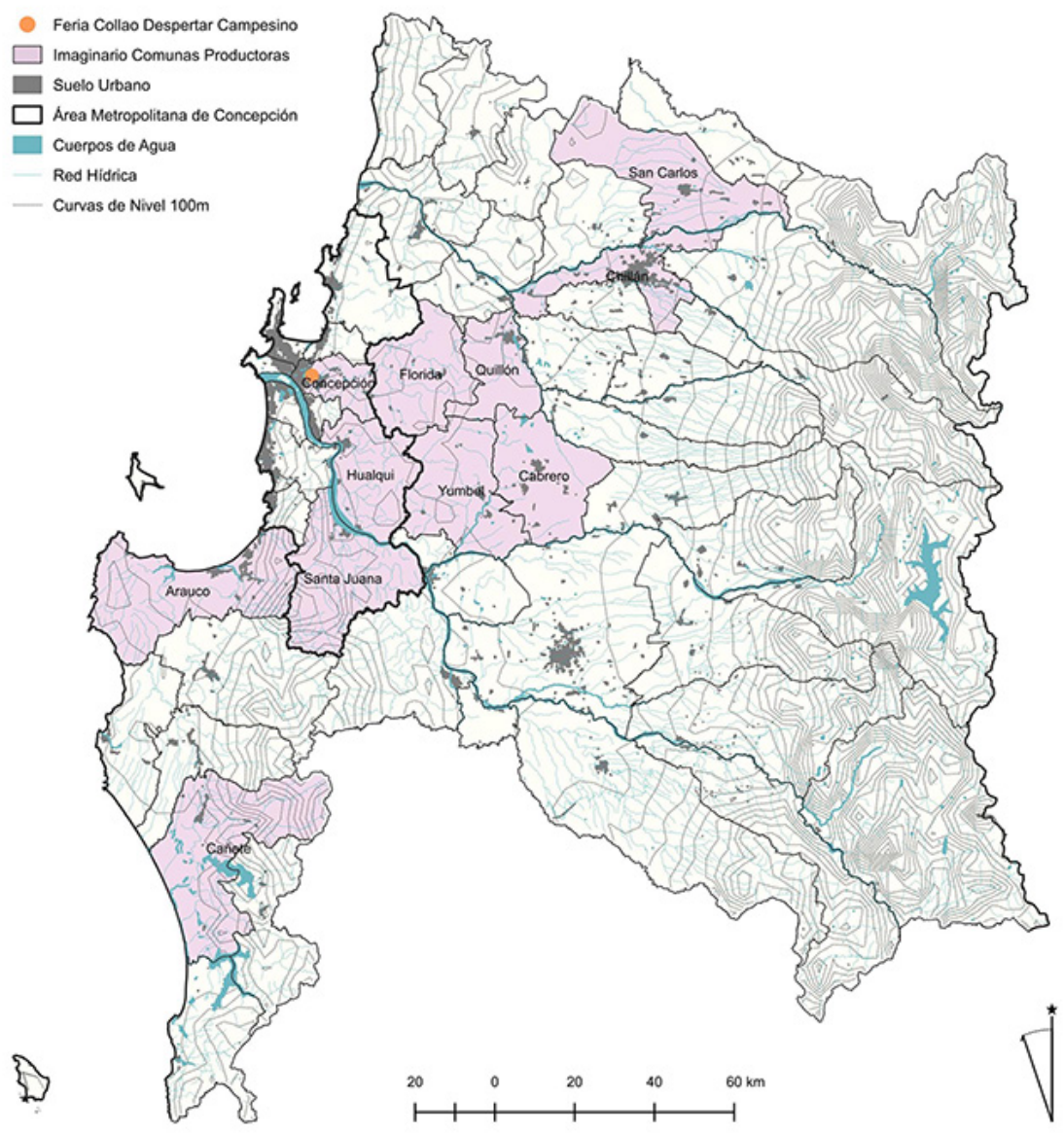

Fuente: elaboración de los autores. 
origen de los productos tenían del imaginario vinculado a la feria. De entre ellos, sólo el 6,5\% definía esta proximidad de forma abstracta, mientras que el 32,8\% era capaz de definir las comunas vinculadas a la producción de los alimentos de la lista proporcionada. Esto implica que el imaginario territorial local que los entrevistados poseen asociado a la feria de Collao tiene un alto nivel de concreción ya que son capaces de proporcionarle un ámbito geográfico y, por tanto, un límite.

Cuadro $\mathrm{N}^{\circ} 2$

Escala del imaginario territorial vinculado a la feria de Collao

\begin{tabular}{|c|c|}
\hline CHILE & $60,8 \%$ \\
\hline Norte & $58,9 \%$ \\
\hline Sur & $1,9 \%$ \\
\hline LOCAL & $39,2 " \%$ \\
\hline Abstracto & $6,5 \%$ \\
\hline Territorializado en comunas & $32,8^{\prime \prime} \%$ \\
\hline
\end{tabular}

Fuente: elaboración de los autores.

Complementariamente, la definición de las comunas que los entrevistados identificaban como orígenes de los productos de la lista permitió construir el mapa del imaginario territorial asociado a la feria de Collao (Figura No 2). Este mapa revela que 11 comunas del ámbito birregional Bío Bío y Ñuble pertenecen a este imaginario. De ellas sólo tres pertenecen al Ámbito Metropolitano de Concepción, dejando fuera del imaginario a las comunas de San Pedro de la Paz, Coronel, Lota, Chiguayante, Hualpén, Penco y Tomé, algunas de las cuales poseen espacios de agricultura intrametropolitana. Por otra parte, se identifican otras ocho comunas distribuidas en un corredor norte-sur que se localiza de forma paralela al corredor agroindustrial del valle central chileno. Estas comunas son San Carlos, Chillán, Quillón, Florida, Cabrero, Yumbel, Arauco y Cañete.

\section{La cuenca alimentaria de la feria de Collao}

Los resultados obtenidos en el catastro realizado en el segundo bloque metodológico se visualizan en la Figura $N^{\circ} 3$. El mapa de la cuenca alimentaria muestra que el origen de los productos catastrados en la feria de Collao se reduce a 4 comunas productoras de los productos seleccionados para la encuesta. Estas comunas son Penco, Santa Juana, Florida y Yumbel, las dos primeras pertenecen al Área Metropolitana y las otras dos se ubican en el primer anillo exterior a ella. Esto implica que los alimentos proceden de una distancia no mayor a $60 \mathrm{~km}$.

Por otra parte, la cuenca no incluye Concepción, la comuna en la que se desarrolla la feria, lo que se debe a la inexistencia o escasez de pequeña agricultura campesina en su suelo. Sin embargo, aparece como comuna intermediaria, ya que algunos de los productos catastrados en los puestos vinculados al "Despertar Campesino" procedían de la Vega Monumental, el gran nodo logístico agroalimentario metropolitano. Esto es debido a que no todos los puestos campesinos se limitan a comercializar su producción, si no que buscan diversificar la oferta con productos de fuera de temporada. 
Figura No 3

Mapa de la cuenca alimentaria vinculada a la feria de Collao.

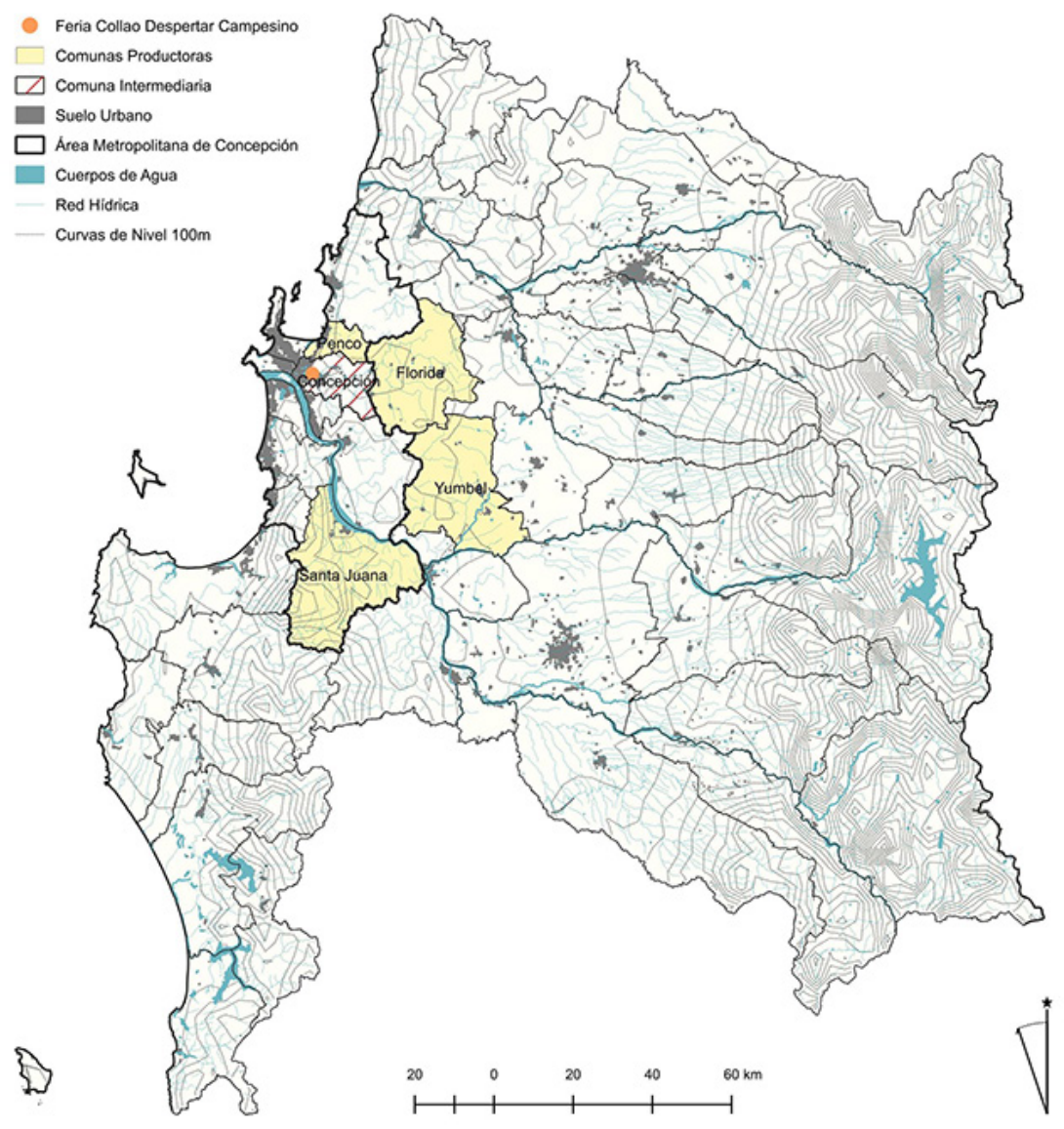

Fuente: Elaboración de los autores en el marco del proyecto DIUBB 170401 2/I

\section{Análisis comparativo entre la cuenca real y la imaginada de la feria de Collao}

Un primer análisis comparativo para detectar convergencias y divergencias entre imaginario territorial y cuenca alimentaria se realiza en relación a las comunas asociadas a cada uno de ellos $y$, a la escala que el conjunto de comunas configura como huella de suelo agrario vinculado con la feria de Collao. El imaginario territorial incluye 11 comunas entre las que se encuentra algunas como Cañete, conocida como proveedora por excelencia de papas, y Chillán o San Carlos, reconocidos por la producción de frutas y hortaliza a gran escala. Sin embargo, el mapa de la cuenca alimentaria nos muestra que sólo cuatro comunas, dos metropolitanas (Santa Juana y Penco) y 
dos del primer anillo (Florida y Yumbel), son las proveedoras de los productos seleccionados para el estudio.

Desde el punto de vista de la dimensión territorial, y derivado de lo anterior, el análisis de los dos mapas indica la diferencia de escalas en el radio de alcance entre el imaginario territorial y la cuenca alimentaria. Para el primero, el radio son $120 \mathrm{~km}$ desde la feria de Collao, mientras que para el segundo son $60 \mathrm{~km}$, es decir, la mitad. El imaginario abarca comunas con un carácter rural o campesino dentro de la región, sin llegar a alcanzar aquellas que se encuentran en el valle central, con una mayor orientación agroindustrial. Sin embargo, la escala de la cuenca es metropolitana.

Figura $\mathrm{N}^{\circ} 4$

Comparación entre radio de alcance de comunas asociadas al imaginario y a la cuenca alimentaria.

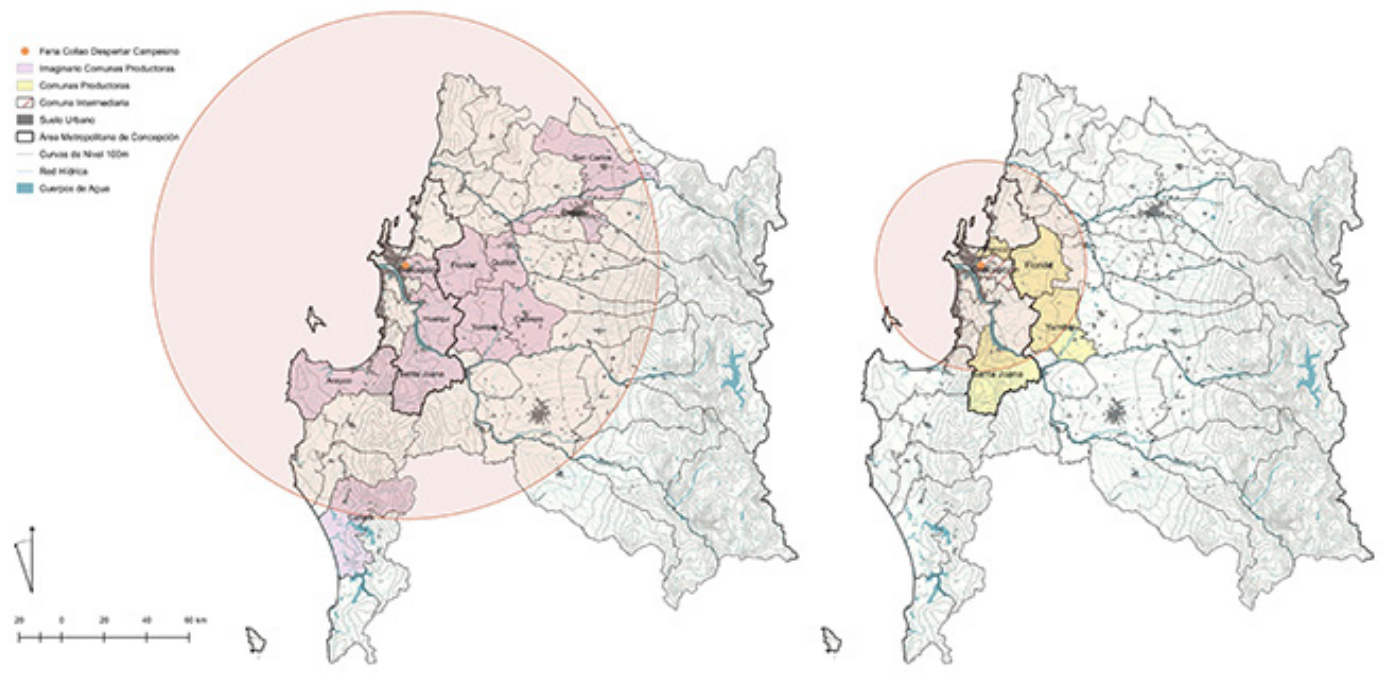

Fuente: elaboración de los autores.

Cuadro $\mathrm{N}^{\circ} 3$

TABLA COMPARATIVA DE ORÍGENES POR PRODUCTOS

\begin{tabular}{|l|l|l|}
\hline & \multicolumn{1}{|c|}{ Imaginario territorial } & \multicolumn{1}{c|}{ Cuenca alimentaria } \\
\hline Acelga & Concepción, Florida, Chillán & Florida, Penco, Santa Juana, Yumbel \\
\hline Ajo & Concepción, Florida, Chillán & Vega Monumental, Yumbel \\
\hline Brócoli & Concepción, Chillán & Penco \\
\hline Cebolla & Concepción, Florida, Chillán & $\begin{array}{l}\text { Vega Monumental, Florida, Santa Juana, } \\
\text { Yumbel }\end{array}$ \\
\hline Cebollín & Florida & Florida \\
\hline
\end{tabular}




\begin{tabular}{|l|l|l|}
\hline \multicolumn{1}{|c|}{ Imaginario territorial } & \multicolumn{1}{c|}{ Cuenca alimentaria } \\
\hline Cerezas & Chillán, Quillón & Florida, Hualqui \\
\hline Changle & Chillán & Florida \\
\hline Choclo & Hualqui, Chillán, Temuco, Arica & Vega Monumental \\
\hline Cilantro & Concepción, Florida, Chillán & Florida, Penco, Santa Juana, Yumbel \\
\hline Digüeñes & Chillán & Florida \\
\hline Huevos & Sin especificar & Florida, Yumbel \\
\hline Lechuga & $\begin{array}{l}\text { Concepción, Florida, Lota, } \\
\text { Chillán }\end{array}$ & Florida, Penco, Yumbel \\
\hline Limón & Arica & Vega Monumental, Florida \\
\hline Manzana & $\begin{array}{l}\text { Florida, Santa Juana, Chillán, } \\
\text { San Carlos }\end{array}$ & Vega Monumental \\
\hline Membrillo & Florida, Hualqui, Santa Juana & Florida, Santa Juana \\
\hline Miel & Florida, Santa Juana, Quillón & Florida, Yumbel \\
\hline Palta & Arica & Vega Monumental \\
\hline Papa & Cañete, Cabrero & Florida, Santa Juana \\
\hline Perejil & Florida & Florida, Penco, Santa Juana, Yumbel \\
\hline Porotos & Cebrero, Yumbel & Yumbel, Florida, Santa Juana \\
\hline Tomate & Copiapó, Talca, Chillán, Quillón & Vega Monumental \\
\hline
\end{tabular}

Fuente: Elaboración de los autores

Profundizando más en los orígenes reales e imaginados de cada uno de los productos (Cuadro $N^{\circ} 3$ ), las comunas identificadas más veces como productoras en el imaginario territorial son Chillán (12/21) y Florida (10/21), mientras que el resto de respuestas diversifica los orígenes en las otras nueve comunas y en algunas localizaciones del norte. Por otra parte, las comunas productoras que más alimentos proporcionan a la feria son Florida (13/21), Yumbel (8/21), Santa Juana (7/21) y Penco (5/21).

El análisis de las coincidencias entre el imaginario territorial local y la cuenca alimentaria indica que Florida es la única comuna que se repite de forma significativa (8/21). De este resultado, se puede deducir que Florida es la única comuna que los asistentes conocen su real capacidad productora y proveedora de productos a la feria de Collao. El caso contrario es Chillán que, si bien es reconocido como productor y proveedor de 12 productos, el catastro demuestra que ninguno de los productos catastrados procede de ella. Complementariamente, otra de las coincidencias es que los productos cuyo origen es claramente no regional, debido a las características del producto o a la estacionalidad, los asistentes a la feria son capaces de identificar que provienen de otras áreas de Chile, como así demuestra la columna de la cuenca alimentaria. 
Figura No 5

Comunas coincidentes entre imaginario y catastro, y su aporte en porcentaje al total de productos catastrados de la feria Collao.

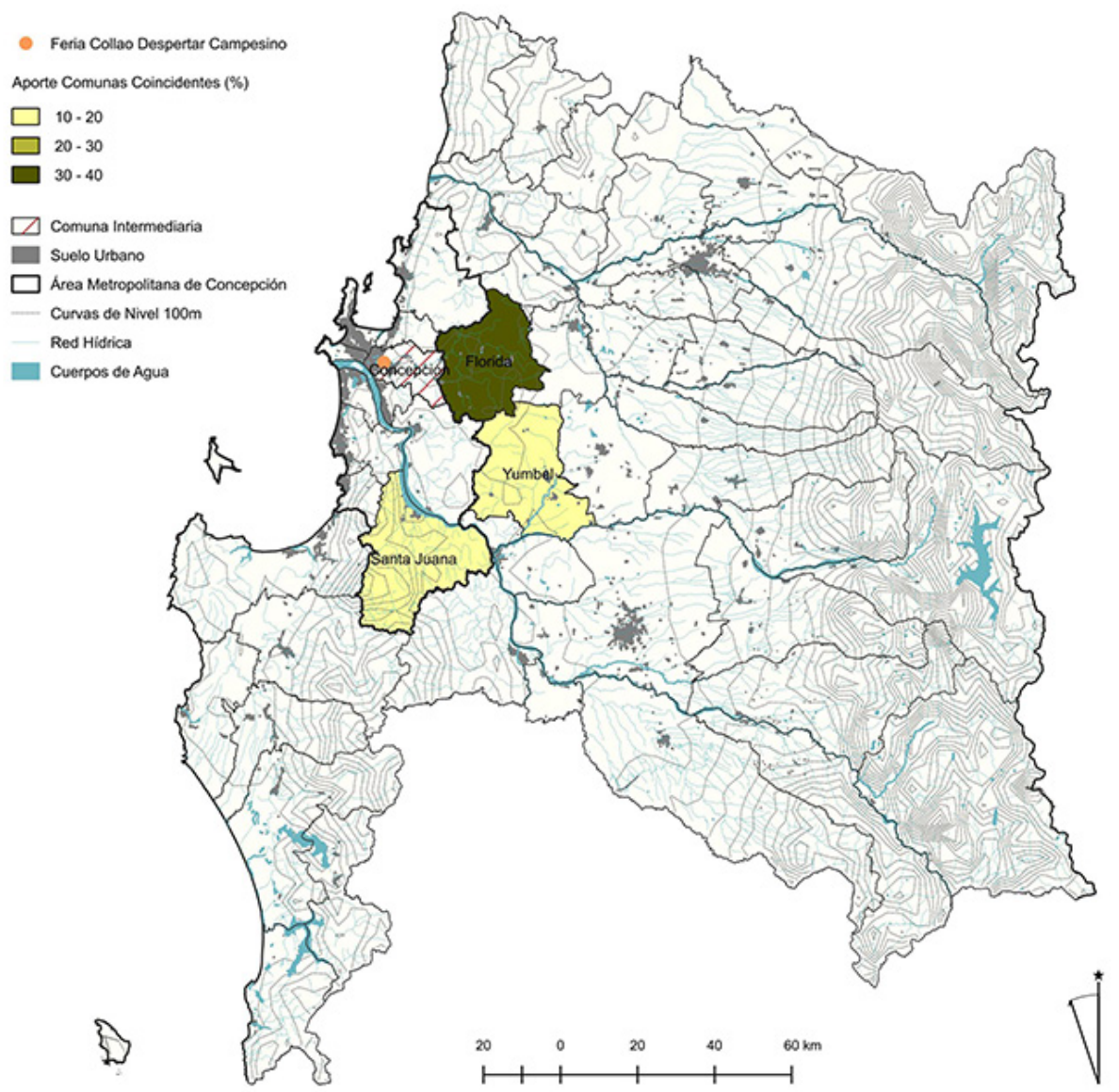

Fuente: Elaboración de los autores

\section{Discusiones}

Razones e implicaciones de las divergencias entre la cuenca alimentaria real y la imaginada

Los resultados demuestran que, a pesar de tratarse de una feria campesina, la dimensión ética no genera un alto nivel de coincidencia entre el imaginario territorial y la cuenca alimentaria real, refutando la hipótesis planteada.

Una de las razones en las que se puede basar este desacople en la feria de Collao es que, a pesar de que las razones de asistencia éticas se equiparan a las utilitarias en un 50\%, los resulta- 
dos arrojan que existe un conocimiento errado del origen concreto de los alimentos. Esto implica que, aunque sus razones de compra sean éticas, no implican un intercambio de información que profundice en el papel de lo que supone la compra de productos de proximidad en términos de origen de los alimentos, economía regional o mantenimiento de usos tradicionales, razón de existencia de las ferias campesinas. Por tanto, se puede decir, que en la feria de Collao el intercambio económico no conlleva un intercambio cultural (Fritz \& Martino, 2009).

El desacople antes mencionado pone de relevancia el desconocimiento efectivo por parte de la ciudadanía de los usos de suelo agrícola existentes tanto dentro del AMC como en su entorno inmediato y, por tanto, de la realidad territorial metropolitana. Esto puede derivar de que, dentro de la complejidad funcional existente en el AMC, que implica actividades productivas primarias y terciarias, son las de carácter urbano las predominantes en el imaginario social, invisibilizando casi por completo las primarias desarrolladas en los espacios agrario intrametropolitanos. El imaginario agroalimentario levantado sostiene una aproximación dual sobre el territorio, donde lo rural solo existiría en el extrarradio metropolitano y, por consiguiente, la metrópolis es, en su totalidad, una cuestión urbana. Por lo anterior, es factible pensar que los habitantes del AMC, no logran imaginar la complejidad funcional de esta singular metrópolis que, en su interior sigue manteniendo activos espacios agrarios de alta productividad (Alarcón et al, 2019).

La invisibilización de estos espacios productivos metropolitanos también se ha producido en los instrumentos de planificación, donde no son recogidos, protegidos ni promovidos, obligándoles a adoptar un papel pasivo de espacios en blanco (Rodríguez, 2010) capaces de absorber infraestructuras $u$ otros crecimientos urbanos más rentables a corto plazo. Esto implica que, en la actualidad, no existe una visión de estos espacios como estratégicos para la seguridad alimentaria urbana sobre los que se puedan aplicar políticas públicas de reconexión (Morgan, 2009)

\section{Lo local como escala maleable}

Frente a otras formas de entender lo local, como la distancia geográfica, entre los agentes o cultural (Feagan, 2007) este artículo se centra en el enfoque de que lo local está vinculado a la escala de aprovisionamiento alimentario (Zazo et al, 2019) y, más concretamente, al área que mantiene las relaciones urbano-rurales que se construyen en la feria de Collao a través de los alimentos. Los resultados del análisis comparativo entre la dimensión territorial de la cuenca alimentaria real y de la imaginada de la feria de Collao ponen de relevancia la maleabilidad de esta escala de lo "local" (Paül \& McKenzie, 2013). El uso de dos parámetros, alcance y dispersión, pueden colaborar a matizar la discusión sobre los resultados.

Por un lado, es relevante profundizar en las razones por las que la cuenca alimentaria posee la mitad del radio de alcance que el imaginario territorial en su distribución espacial. En el caso de la cuenca alimentaria la escala de lo local corresponde a una escala que implica una distancia máxima de $60 \mathrm{~km}$. Esto se debe a que la feria campesina de Collao es la representación territorial del tipo de asociación que se establece en el sindicato Despertar Campesino. Esta feria está basada en un colectivo de feriantes-productores que se asocian para aprovisionar a Concepción de alimentos frescos que tienen la feria de Collao como su nodo de unión. Esto marca la diferencia con otras ferias campesinas metropolitanas que surgen como agrupaciones de productores de un mismo espacio agrario que deciden ofrecer sus productos a los ciu- 
dadanos de su comuna mediante la organización de una feria. La cuenca alimentaria en esos casos resulta ser mucho más reducida, siendo habitualmente de escala comunal. Sin embargo, en el caso de Collao la huella abarca un radio de alcance metropolitano que resulta ser el límite que los productores asumen para acercarse a la feria tres veces por semana. En el caso del imaginario territorial, no existen esos límites de distancia asociados a cuestiones prácticas y las respuestas de los asistentes en cuanto al origen de los alimentos tienen que ver con la imagen de la capacidad productiva de las comunas.

Por otra parte, en ninguno de los dos casos las cuencas están conformadas por comunas aledañas o grandes áreas agrícolas si no que, por el contrario, se trata de cuencas dispersas. En el caso de la cuenca alimentaria, esto puede deberse a que se trata de aquellos municipios que, además de poseer un fuerte carácter rural o bien no poseen otros canales de comercialización que reconocen el valor de la proximidad por los que dar salida a estos productos o bien estos canales comunales no son capaces de absorber la producción generada. En el caso del imaginario territorial la escala de lo local se relaciona con la imagen de comunas productoras que proyectan en el ámbito birregional, más que con un intercambio de información con los feriantes en el momento de la compra de productos.

Bajo el enfoque utilizado, en ambos resultados podría aplicarse el concepto de lo "local" resultando en cuencas muy diferentes. Las razones subyacentes que configuran ambas escalas son las que conducen a que no existe coincidencia entre ambas cuencas. Por tanto, la flexibilidad del término indica la imposibilidad de delimitarlo en términos espaciales y entenderlo como una escala abstracta y variable bajo un mismo enfoque.

\section{Conclusiones}

El estudio desarrollado demuestra que, a pesar de que la feria de Collao es una feria campesina, la dimensión ética no genera un alto nivel de coincidencia entre el imaginario territorial y la cuenca alimentaria real, refutando la hipótesis planteada. El estudio sugiere que, a pesar de que la mitad de los asistentes compra por alguna razón ética, el intercambio económico no conlleva un intercambio cultural, no suponiendo un afianzamiento del vínculo entre ciudadano y productor, en el que se basan las relaciones urbano-rurales de abastecimiento alimentario, y siendo las razones utilitarias y hedónicas las que representan la asistencia a la feria. El desacople también sugiere un desconocimiento por parte de los ciudadanos de la complejidad funcional existente en el AMC que viene reforzada por su invisibilización tanto en los instrumentos de planificación como en las políticas públicas. En este sentido se hace necesario profundizar en el análisis de otras ferias campesinas que no posean este carácter dual o cuyas agrupaciones de feriantes posean otras características diferentes para verificar si en ellas también existe este desacople y profundizar en sus razones e implicaciones.

Por otra parte, el enfoque de lo local utilizado conduce a la reflexión de que los resultados de ambos bloques de la investigación dan lugar a diferentes escalas del ámbito local relacionado con la feria de Collao, confirmando la maleabilidad y flexibilidad del término y cuestionando la posibilidad de delimitar lo local. 
El artículo pone de relevancia que el estudio de la cuenca alimentaria de las ferias campesinas implica el análisis de las relaciones urbano-rurales vinculadas a ella. Así como que el análisis de la trazabilidad de los alimentos, real y/o imaginada, implica el análisis indirecto de las razones subyacentes de la compra y de las implicaciones de las mismas.

\section{Agradecimientos}

Esta investigación ha sido desarrollada en el marco del proyecto interno regular DIUBB 193101 $1 / R$, y dentro del Grupo de Investigación Espacio, Sociedad y Conflicto de la Universidad del Bío Bío GI 195501/EF.

Los autores agradecen la colaboración realizada por Felipe Garrido, alumno de seminario en el trabajo de campo, y por Isidora Troncoso, ayudante de investigación, en el trabajo de campo y elaboración de documentación gráfica.

\section{Referencias bibliográficas}

ALARCÓN, M.; del PINO, M; FERNÁNDEZ, S. \& SOTO, J. Prácticas agroecológicas en territorios rururbanos del Área Metropolitana de Concepción. Aportes desde la Economía Social y Solidaria a la sustentabilidad urbana. Urbano, 2019, pp: 42-63.

ALISTE, E. \& ALMENDRAS, A. Trayectoria territorial de la conurbación Concepción-Talcahuano: industria, asentamientos humanos y expresión espacial del desarrollo, 1950-2000. En PEREZ, L. e HIDALGO, R. (ed). Concepción Metropolitano. Evolución y desafíos. Santiago de Chile: Pontificia Universidad Católica de Chile, Serie GEOlibros y Centro EULA, Universidad de Concepción, 2010, p 123-149.

AUROUSSEAU, M. The distribution of population a constructive problem, en The Geographical Review, 1921, 11 (4), pp: 563-592.

ÁVILA, B. \& CRUZ, K. Sacar a mil: ferias libres en el Gran Concepción. Reducto de consumo premoderno y ¿generador de diversidad social? Tesis de seminario de grado de Arquitectura. Universidad del Bío Bío, 2016.

BAUDRILLARD, J. El sistema de los objetos. Ciudad de México: Ed. Siglo XXI, 1969.

BELL, D. Las contradicciones culturales del capitalismo. Madrid: Alianza, 2006.

Bell, C. \& Beeston, H. Farmers' Markets: commoditizing New Zealand rural identity myths. Social Space Scientific Journal 2, 2011, pp: 57-74.

BERNABÉ, A. (coord.). Las ferias campesinas: una estrategia socioeconómica. Estudio realizado en la provincia Cercado y Saucarí en Oruro. La Paz: PIEB, 2002. 
CAMPBELL, C. The Romantic Ethic and the Spirit of Modern Consumerism. Cambridge: Blackwell Publishers, 1995.

DE CERTEAU, M. The Practice Of Everyday Day Life. California: University Of California Press, 2002.

FEAGAN, R. The place of food: mapping out the 'local' in local food systems, Progress in Human Geography, 2007, 31, pp: 23-42.

FRITZ, M. \& MARTINO, G. (2009). Short Food Supply Networks: Expectations, Experiences, Trust in the Case of Farmers Markets. En Fritz, M; Rickert, U. \& Schiefer G (ed). System Dynamics and Innovation in Food Networks, 2009, pp: 409-422.

GETZ, A. Urban foodsheds. Permaculture Activist. 1991, 24, pp: 26-27.

GOSS, J. The Magic of the Mall: An analysis of form, function, and meaning in the contemporary retail environment. Annals of the Association of American Geographers, 1993, 83 (1), pp: 18-47.

HERNÁNDEZ, H. El Gran Concepción: Desarrollo histórico y estructura urbana. Revista Informaciones Geográficas, 1983, 30, pp: 47-70.

HIDALGO, R.; de SIMONE, L.; SANTANA, D. \& ARENAS, F. Geografías del comercio en Santiago de Chile (1990-2010): de la reestructuración comercial al policentrismo inmobiliario. Revista Geográfica Venezolana, 2016, 57 (1) pp: 14-37.

KIRWAN, James. Alternative strategies in the UK agro-food system: interrogating the alterity of farmers' markets. Sociologia ruralis, 2004, 44 (4), pp: 395-415.

LINDERS, H. Consumo ético, consumo saludable: ¿Existe un nuevo consumidor en América Latina?. En Agricultura familiar y circuitos cortos: Nuevos esquemas de producción, comercialización y nutrición. Memoria del seminario sobre circuitos cortos realizado el 2 y 3 de septiembre de 2013. Santiago: CEPAL, 2014. LC/L. 3824. p. 57-62.

LINDÓN, A. La ciudad y la ida urbana a través de los imaginarios urbanos. EURE, 2007, 33(99), 7-16.

LIPOVETSKY, G. La felicidad paradójica. Ensayo sobre la sociedad de hiperconsumo. Barcelona: Anagrama, 2007.

MÁRQUEZ, F. Imaginarios Urbanos en el Gran Santiago: Cuencas de una metamorfosis. Revista Eure, 2007, XXXIII, (99), pp. 79-88.

MILLER, D. Material Culture and Mass Consumption. Cambridge: Blackwell Publishers, 1995.

MITRE, E. Ciudades medievales europeas: entre lo real y lo ideal. Madrid: Catedra, 2013, 352 pp.

MORA, R.. Comercio informal y estructura urbana periférica: una metodología de análisis de las ferias libres. Revista INVI, 2003, vol. 18, no 48, p. 106-114. 
MORGAN, K. Feeding the city: The challenge of urban food planning. International Planning Studies, 2009, 14 (4), pp: 341-348.

NAPADENSKY, A. Centros tradicionales, nuevas centralidades y descentralización en metrópolis intermedias latinoamericanas Caso del Gran Concepción. Cuaderno Urbano. Espacio, Cultura, Sociedad, 2016, 21, pp. 29-56.

NAPADENSKY, A. y ORELLANA, A. Metropolización y organización funcional de sistemas urbanos intermedios. Gran La Serena, Concepción y Puerto Montt. Bitácora Urbano Territorial, 2019, 29 (1): 65-78.

NAPADENSKY, A., \& RIVERA, F. Espacios genéricos y apropiaciones sociales en centros comerciales: El caso del Mall Plaza del Trébol en el área metropolitana de Concepción, 1994-2012. Urbano, 2015, 18 (31), pp: 32-51

ODEPA. Informe final. Estudio de la caracterización del canal feria para la distribución de productos hortofrutícolas V y VIII Región. Santiago de Chile: Ministerio de Agricultura. ODEPA, 2009.

PAÜL, V. \& MCKENZIE, F. Peri-urban farmland conservation and development of alternative food networks: Insights from a case-study area in metropolitan Barcelona (Catalonia, Spain). Land Use Policy, 2013, 30, 94-105.

PEÑALOZA, V., DENEGRI, M., \& GERHARD, F. ¿Vamos a la feria? Un estudio sobre las motivaciones para frecuentar las ferias libres. Pensamiento \& Gestión, 2015, 38, 16-32.

PETERS, C.; BILLS, N.; LEMBO, A.; WILKINS, J.; FICK, G. Foodshed analysis and its relevance to sustainability. Renew. Agric. Food Syst. 2009, 24, 72-84.

RATZEL, F., Anthropogeographie, 1891. Cit. Por Capel, H., La definición de lo urbano. Estudios geográficos,1975, 138-139, pp: 265- 301

RICHTHOFEN, F. Vorlessungen über allgemeine Siedlungs- und Verkehrsgeographie, 1908. Cit. Por Capel, H., La definición de lo urbano. Estudios geográficos, 1975, 138-139, pp: 265-301.

RODRÍGUEZ, M. Vacíos, espacios agrarios, intersticios metropolitanos del amc: Oportunidades para un proyecto territorial. En PEREZ, L. e HIDALGO, R. (ed). Concepción Metropolitano. Evolución y desafíos. Santiago de Chile: Pontificia Universidad Católica de Chile, Serie GEOlibros y Centro EULA, Universidad de Concepción, 2010, pp: 253-258.

ROLDÁN, H. N., GRACIA, M. A., SANTANA, M. E., \& HORBATH, J. E. Los mercados orgánicos en México como escenarios de construcción social de alternativas. Polis. Revista Latinoamericana, 2016, vol.15, n.43, pp.581-605.

SALAZAR, G. Ferias libres: espacio residual de soberanía ciudadana. Santiago de Chile: Ediciones Sur, 2003. 
SENNETT, R. La cultura del nuevo capitalismo. Barcelona, España: Anagrama, 2006.

SERCOTEC. Catastro Nacional de ferias libres. Santiago de Chile: gerencia de comunicaciones Sercotec, 2016.

TRONCOSO, C. La feria libre como fenómeno de centralidad transitoria. Desafíos del diseño urbano ante las transformaciones de la actividad comercial ferial en Santiago. El caso de la comuna de Macul. Santiago de Chile: Macul, 2009.

UTRERAS, P. La feria libre como pieza urbana: estudio sobre el valor urbano de las ferias libres y propuesta de un modelo de evaluación de su sustentabilidad territorial. Santiago de Chile: Pontificia Universidad Católica de Valparaíso, 2013.

VERDÚ, V. Yo y tú, Objetos de lujo. El personismo: La primera revolución cultural del siglo XXI. Barcelona: DeBolsillo, 2007.

ZAZO, A.; TRONCOSO, I. Outlining the alternativeness of urban and peasant food networks in the global south. A case study in the concepción metropolitan area (Chile). En Infinite Rural Systems in a Finite Planet: Bridging Gaps towards Sustainability; Paül, V., Lois, R., Trillo, J.M., McKenzie, F., Eds.; Universidad de Santiago de Compostela Publicaciones: Santiago de Compostela, Spain, 2018; pp. 67-76.

ZAZO, A.; TRONCOSO, I.; MOREIRA, A. Regenerative Food Systems to Restore Urban-Rural Relationships: Insights from the Concepción Metropolitan Area Foodshed (Chile). Sustainability 2019, $11,2892$. 
